Revue d'histoire de l'Amérique française

REVUE D.HISTOIRE DE L'AMÉRIQUE FRANÇAISE

\title{
MONARQUE (Georges), Un Général allemand au Canada; le baron Friedrich Adolphus Von Riedesel. Montréal 1946. 151 pages
}

\section{Liliane Rinfret}

Volume 2, numéro 1, juin 1948

URI : https://id.erudit.org/iderudit/801441ar

DOI : https://doi.org/10.7202/801441ar

Aller au sommaire du numéro

Éditeur(s)

Institut d'histoire de l'Amérique française

ISSN

0035-2357 (imprimé)

1492-1383 (numérique)

Découvrir la revue

Citer ce compte rendu

Rinfret, L. (1948). Compte rendu de [MONARQUE (Georges), Un Général

allemand au Canada; le baron Friedrich Adolphus Von Riedesel. Montréal 1946.

151 pages]. Revue d'histoire de l'Amérique française, 2(1), 132-134.

https://doi.org/10.7202/801441ar d'utilisation que vous pouvez consulter en ligne.

https://apropos.erudit.org/fr/usagers/politique-dutilisation/ 
MONARQUE (Georges), Un Général allemand au Canada; le baron Friedrich Adolphus Von Riedesel. Montréal 1946. 151 pages.

Le passage de troupes mercenaires allemandes sur notre continent, à l'occasion de la révolution américaine, n'aurait pas tenu beaucoup de place dans la littérature historique si ces troupes n'avaient été sous le commandement du major-général 
Riedesel. Le baron hessois et sa femme, d'esprit fin et cultivé, ont laissé des mémoires, lettres et journaux. Un américain, William L. Stone, les a traduits et publiés dans les Munsell's Series of Local American History, volume 6, 8 et 9. C'était rendre accessible une importante source de documents que Monarque n'a pas manqué d'exploiter, car, même s'il ne nous renvoie pas à l'édition de Stone, son ouvrage en apparaît souvent une traduction résumée.

En 1775, pour faire face aux rebelles de Boston qui se disposent à envahir le Canada, Carleton ne dispose que de 900 hommes. Il demande du secours à Londres, mais repoussera seul les armées d'Arnold et de Montgomery: les renforts arriveront trop tard. Lord Germaine avait dû engager des troupes étrangères à la hâte. Sur un total de 16,900 soldats allemands, le duc de Brunswick en cédait environ 4,000 et les confiait à Friedrich-Adolphus Von Riedesel, qu'il créait major-général. Celuici, de vieille noblesse, s'était illustré dans la guerre de Sept Ans et n'avait connu que des victoires. Il était âgé de 37 ans. Il venait mouiller à Québec avec une partie de ses troupes le 1er juin 1776 .

Le gouverneur anglais songe alors à refouler les Américains puis à aller les combattre sur leur propre territoire. Cette première année, on doit se contenter d'un engagement naval sur le lac Champlain. Riedesel établit ses quartiers-généraux a Trois-Rivières pour passer son premier hiver au pays.

Au mois de mai suivant, Burgoyne remplaçait Carleton et devenait commandant en chef. Il tenait du ministre Geımaine un plan de campagne qui lui enjoignait d'operel une jonction sur la rivière Hudson avec deux autres armées parties, l'une du lac Ontario, l'autre de New-York. Madame de Riedesel et ses trois filles venaient de toucher le sol canadien alors que son mari se mettait en marche avec 3,958 Bruns. wickers. La courageuse femme prit le parti de le suivre avec ses enfants. Après quelques contacts avec l'ennemi, c'est la rencontre désastreuse de Bennington, prélude de la reddition à Saratoga. Selon une convention avec le général américain Gates, Burgoyne s'assurait le transport de ses troupes en Angleterre via Boston. Elles vécurent un an dans des conditions sordides à Cambridge, puis furent soumises à une marche harassante de 678 milles jusqu'en Virginie, où elles allaient demeurer jusqu'à la libération de $\mathbf{1 7 8 3}$. Riedesel et sa famille accompagnèrent l'infortunée aile gauche allemande. Cependant, en 1780, un échange leur permit de demander leur retour à Québec.

C'est le nouveau gouverneur Haldimand qui les accueille, à l'automne de 1781 . Il confie au général le poste de Sorel à cause de son importance stratégique et voit à lui faire construire une maison confortable que Monarque dit exister encore. La baronne jouit beaucoup de son séjour ici. Nous gardons d'elle d'agréables descriptions: le passage d'une volée de pigeons sauvages qui termineront leur migration dans un " pâté de tourtres ", la pêche aux petits poissons des chenaux, une visite aux chutes Montmorency. Les Allemands, de leur côté, exercent un certain charme sur les Canadiennes, car, quand survient le rapatriement, Riedesel ne laissera pas en terre américaine seulement les vaillants dragons, chasseurs ou grenadiers morts pour la cause de George III. Douze cents soldats demeurent au Canada et donnent de nombreux descendants, qui, sans Monarque, n'auraient peut-être jamais soupçonné leur sang germanique. 
Nous souligons, au début, que cette biographie ne nous renvoie pas aux travaux de Stone et pourtant, entre autres passages, nous relevons, volume I, page 42, des Memoirs and Letters and Journals, of Major General Riedesel, During his Residence in America: "On the same day he received from General Carleton the command of a separate corps, a distinction which was entirely unexpected ». Nous retrouvons dans Monarque, page 32: "Le même jour, Riedesel reçut de Carleton le commandement inattendu d'un corps séparé ». Nous aurions aimé également que l'auteur consultât l'énorme Collection Haldimand. J.-E. Roy l'avait dépouillée pour déclarer dans son Histoire de la Seigneurie de Lauzon, volume III, chapitre cinquième, page 70: "Ces soldats avaient la rudesse teutonne et l'insolence des rheitres [sic] mal appris». Riedesel était déjà un maître en espionnage pour le compte de Ferdinand de Brunswick. La sale besogne que lui confia Haldimand à l'égard de braves colons ternit le bon souvenir que les Canadiens pourraient garder de cet étranger de marque. Le livre de Monarque est trop bienveillant, il manque totalement de rigueur, de méthode. De plus, il est écrit en mauvais français. Il convainc toutefois le lecteur, lors de sa prochaine visite à Sorel, de s'enquérir de la Place des Canons, de la maison des Riedesel et de l'emplacement des casernes. Il a sûrement intéressé au plus haut point les Globensky, les Bender, les Piuze, les Payer, les Grothé, qui, nous l'espérons, nous donneront un jour une histoire originale et complète de leurs ascendants Brunswickers.

Liliane RINFKET

N.D.L.D. - On nous pardonnera de publier les deux comptes rendus précédents en caractères 8/10, caractères auxquels, on l'aura constaté, nous avons définitivement renoncé, sauf pour les références au bas des pages. Ces deux comptes rendus avaient été préparés pour la livraison de mars de la Revue. 